\title{
Slow Medicine
}

\author{
Elena Hill, $M D, M P H$
}

This is an opinion piece that examines the dichotomy of "fast medicine" (which involves high medical use and spending) and what I refer to as "slow medicine". It discusses ethical questions around which of these two frameworks really confers better "health" to patients - using examples from a real patient scenario of mine who was considering undergoing a relatively high-risk carotid endarterectomy. It then re-affirms the importance of primary care to conferring health and the ultimate value of primary care, or "slow medicine". I believe it is a timely discussion as we continue to advocate for more primary care resources in our health care system. ( $\mathrm{J}$ Am Board Fam Med 2021;34:871-873.)

Keywords: Delivery of Health Care, Ethics, Health Resources, Primary Health Care

Americans love "fast medicine": flashy machines, new technologies, and cutting-edge procedures. We get so wrapped up in the million expensive, extensive, and excessive ways that we can treat any condition that we often forget to ask, "How much health are we actually helping our patients obtain? What is health, really? How do we measure it?"

Primary care is, in contrast, what I like to call "slow medicine." In primary care, doctors do not get to whip out big fancy toys-laparoscopic bovies or magnetic resonance imaging machines. Most of our visits involve painstakingly sitting with patients as they tell us about their chronic depression, financial struggles, difficulties locking down a job, or marital violence. It is depressing. It is exhausting. We do not get the satisfaction of walking into the operating room and walking out hours later knowing that we have fixed something in a concrete way. The rewards and little victories are present, of course, but they are less frequent, and they take time.

Primary care doctors feel a lot of pressure, like all doctors, to practice fast medicine- to "do a lot of stuff." Ordering tests, referring to specialists, prescribing an additional medication-these all make

This article was externally peer reviewed.

Submitted 13 September 2020; revised 29 November 2020; accepted 30 November 2020.

From the Family Medicine Attending Physician, Bronxcare Health Systems, Bronx, NY (EH).

Funding: None.

Conflict of interest: None.

Corresponding author: Elena Hill, MD, MPH, 2183 3rd Avenue, New York, New York 110035 (E-mail: ehill3047@ gmail.com). us feel like we are taking action and helping outpatients. But are we?

Recently, I cared for a patient with carotid artery stenosis, a disease where the arteries that bring blood to the brain get clogged, leading to the feared complication of stroke. My patient was to undergo a carotid endarterectomy (CEA), a procedure in which the neck is opened up, and the artery cleaned out of all the gunk to restore blood flow to the brain. Approximately 140,000 CEA are performed in the United States each year. ${ }^{2}$

However, this patient was older and had a lot of other comorbidities. Therefore, I questioned whether an invasive surgery was really a good idea. Like any good doctor, I went to the research. Here is what I found in the literature:

The average patient with carotid artery disease has a $2 \%$ risk of stroke each year. The surgery reduces that risk to $1 \%$ per year. ${ }^{1,3}$

Let us think about this for a second. We put 140,000 individuals through this surgery each year and only manage to decrease their risk of stroke by a mere $1 \%$ per year. Further, the procedure is not a joke. Although it is relatively safe, it still comes with the risks of any surgery, such as heart attack, postoperative bleeding, infection, and of course, the operation itself occasionally causes stroke ${ }^{3}$-oh, the irony! Not to mention the week or more of recovery time.

So, I have to ask, "Would the carotid endarterectomy really ultimately make my patient healthier?"

The truth is, fast medicine does not make us health$i e r .^{7}$ Countless studies show that we have only 
comparable and sometimes worse health outcomes compared with other countries. ${ }^{7}$

Now let us look at slow medicine: My favorite study of all time looked at physician empathy and its effect on the common cold. The study demonstrated that when family physicians saw patients with a common cold and the physician showed empathy for their illness, they actually reported a statistically significantly fewer number of days of that illness. ${ }^{6}$ This is a real and tangible improvement in health. In fact, when you consider the number of inconveniences, lost days of productivity, and discomfort of the common cold as compared with the serious but unlikely risk of stroke, some might argue that shaving a couple of days of illness off of a head cold every couple years is more valuable to the average patient's quality of life than reducing their risk of having a stroke; a stroke that $98 \%$ of the time was not going to happen anyway.

In addition, this entire intervention-empathy, listening, additional time with the patient-is accomplished without spending 1 additional health care dollar.

Intervention is truly the power primary care has to affect health. This is what health care reform should be all about and why primary care really, really matters.

In recent years, the country has shifted its stance on primary care. The Affordable Care Act (ACA)'s emphasis on prevention may have been 1 of the most important components of the law in terms of shifting our frame on health care in coming decades. The ACA expanded preventative and primary health care services $^{4}$ in many ways. It increased funding for the National Health Service Corps, which provides loan repayment for medical students entering primary care. ${ }^{4}$ It eliminated cost-sharing for several preventative and screening services like birth control, colonoscopies, and mammograms. ${ }^{4,7}$ It expanded primary care residency slots to train more primary care doctors. ${ }^{4}$ It created the idea of patient centered medical homes ${ }^{7}$ and increased Medicaid reimbursement for primary care services. ${ }^{4,7}$ The ACA began the implementation of their prevention-focused reforms in 2010 and have allocated over $\$ 15$ billion to the Prevention and Public Health Fund. ${ }^{5}$

This stance is in no way to say that the vascular surgeons, interventional cardiologists, and neurosurgeons of the world do not absolutely deserve credit for the wonderful life-saving procedures they perform. However, there are different, more subtle ways to create "health." Numerous studies show the relationship between adequate numbers of primary care providers and improved overall morbidity and higher self-rated health status. ${ }^{7}$

The statistics speak for themselves: Primary care works. Slow medicine works.

So how do I, how do we, implement this in practice?

First, we must start deliberately teaching the concept of slow medicine to our new doctors. As a relatively recent trainee myself, I remember the pressure I felt to overorder and overdiagnose so that my attendings would not criticize me for failing to order a test that they would have ordered. We, therefore, spend money and do invasive procedures as trainees simply to avoid "getting in trouble with the boss."

This action instills the wrong message from early on in our careers. It teaches us to do, instead of to think, or even better, to listen to our patients.

Now, as an attending, when my residents tell me they are going to order "the routine labs," I make a point of stopping them, asking them to tell me which labs and why. I challenge my trainees to tell me why they are ordering everything they are ordering. I ask them to think about whether a procedure or a test will ultimately change what we do for a patient ("will it change management?"). I permit them not to simply order tests because they have been told they are "supposed to." I also let them practice making the choices for themselves, which allows them to think and not simply "do."

As family doctors, we have the opportunity to practice "slow medicine" and to demonstrate this new paradigm by example. This opportunity is our power and our privilege. This opportunity for slow medicine is what "health" really means.

To see this article online, please go to: http://jabfm.org/content/ 33/5/871.full.

\section{References}

1. Dynamed. Carotid Artery Stenosis Repair - Prognosis. Available from: http://www.dynamed.com/topics/ $\mathrm{dmp} \sim \mathrm{AN} \sim \mathrm{T} 116305 /$ Carotid-artery-stenosis-repair\# Prognosis. Accessed April 1, 2016.

2. National Institutes for Health. National Institute of Neurological Disorders and Stroke. Questions and Answers about Carotid Endarterectomy. Available from: http://www.ninds.nih.gov/disorders/ stroke/carotid_endarterectomy_backgrounder.htm. Last modified March 21, 2016.

3. Kolk van Der AG, de Borst GJ, Jongen LM, et al. Prevalence and clinical consequences of carotid 
artery residual defects following endarterectomy. Eur J Vasc Endovasc Surg 2011;42:144-152.

4. American Academy of Family Physicians (AAFP). Primary Care in The Affordable Care Act. Available from: http://www.aafp.org/dam/AAFP/documents/ advocacy/coverage/aca/ES-PrimaryCareACA-061311. pdf.

5. United States Department of Health and Human Services. Preventative Medicine. Available from: http://www.hhs.gov/healthcare/about-the-law/preventivecare/index.html.

6. Rakel DP, Hoeft TJ, Barrett BP, Chewning BA, Craig BM, Niu M. Practitioner empathy and the duration of the common cold. Fam Med 2009;41:494501.

7. Davis K, Adams M, Stemikis K. How the affordable care act will strengthen the nation's primary care foundation. J Gen Intern Med 2011;26:1201-1203. 